\title{
Neuron-Glia Interactions of Rat Hippocampal Cells in vitro: Glial-Guided Neuronal Migration and Neuronal Regulation of Glial Differentiation
}

\author{
U. E. Gasser and M. E. Hatten \\ Center for Neurobiology and Behavior, Department of Pathology, College of Physicians \& Surgeons of Columbia \\ University, New York, New York 10032
}

To examine neuron-glia interactions of hippocampal cells, including glial-guided neuronal migration, glial organization of neuronal positioning and neuronal regulation of astroglial differentiation, rat hippocampal tissue, harvested between embryonic day 16 (E16) and postnatal day 3 (P3), was dissociated into a single cell suspension and plated in glass coverslip microcultures (Hatten and Liem, 1981; Hatten et al., 1984). Immunostaining the cells with antibodies against the gllal fllament protein (AbGFP) revealed developmental stage-specific changes in the number and extent of morphological differentiation of hippocampal astroglial cells. At E16-E18, fewer than $5 \%$ of the cells were AbGFP-positive; stained cells were immature, bearing very short processes. By E19-E20, the number of stained cells increased to $15 \%$ of the total cell population. Three forms of differentiated glial cells predominated, a bipolar form bearing processes 30$50 \mu \mathrm{m}$, an elongated form which resembled the radial glia of hippocampus, bearing processes $120 \mu \mathrm{m}$ in length, and a stellate form with 3 or more processes 30-50 $\mu \mathrm{m}$ in length. At P0-P3, glial morphological differentiation varied with the culture substratum; differentiated forms resembling those seen at E20 occurred on Matrigel, but not on polylysine.

Quantitation of the distribution of neurons relative to AbGFP-stained glial processes revealed developmental stage-specific changes in glial organization of neuronal positioning in the cultures. In cultures of E16-E 18 hippocampal cells, the neurons did not preferentially associate with astroglial cells. By E19-E20, extensive neuron-glia interactions occurred, with $80-90 \%$ of the neurons being located within $5-10 \mu \mathrm{m}$ of a glial process.

In addition to their organization of neuronal positioning, E20 hippocampal astroglial cells supported extensive neuronal migration. Migrating hippocampal neurons displayed a cytology and neuron-glia cell apposition identical to that described for migrating cerebellar granule cells in vitro (Edmondson and Hatten, 1987), closely apposing their cell soma

\footnotetext{
Received Sept. 6, 1989; revised Oct. 24, 1989; accepted Oct. 27, 1989.

We are grateful to our colleague Dr. Carol A. Mason for her extensive advice on these experiments and for critically reading the manuscript, and to David Smith and Linda Friedman for thcir assistance in the preparation of Figure 6. Philip Scala provided expert technical assistance and Ray Manson prepared the photographic plates. Supported by NIH grant NS 15429 (M.E.H.), Program Project Grant NS 21457 (M.E.H.), and a grant from the American Paralysis Association.

Correspondence should be addressed to Dr. Mary E. Hatten, Center for Neurobiology and Department of Pathology, College of Physicians \& Surgeons of Columbia I Iniversity, 630 West 168th Street, New York, NY 10032.

Copyright (C) 1990 Society for Neuroscience $0270-6474 / 90 / 041276-10 \$ 02.00 / 0$
}

against the hippocampal glial process and moving along the glial arm by extending a thickened, leading process. Migration was seen only along highly elongated glial profiles resembling radial glial seen in vivo.

The morphological differentiation of hippocampal glial cells in vitro was dependent on cell-cell interactions with neurons. In the absence of neurons, purified hippocampal astroglia had flat, undifferentiated profiles and proliferated rapidly. The addition of hippocampal neurons rapidly arrested glial growth and induced glial process extension.

Although it is now recognized that neuron-glia interactions are important for neuronal migration (Rakic, 1971, 1972, 1978), neurite outgrowth (Tomaselli et al., 1988), and axon guidance (Silver et al., 1982) in the developing mammalian brain, little is known about the regional specificity of these events. In particular, information is lacking on the mechanisms which regulate the expression of molecules requisite for the functional roles of astroglia, either in establishing the architectonics of different cortical regions or in modulating the microenvironment of neurons in mature brain. An important issue is how astroglia vary among brain regions (Barbin et al., 1988).

In recent years, the central role of the hippocampus in learning and memory has spurred research into the mechanisms underlying its cellular organization and connectivity. Although the cytoarchitecture (Issacson and Pribram, 1975) and development of the hippocampus, including its radial pattern of neurogenesis (Ramón y Cajal, 1893; Angevine, 1965; Altman and Das, 1965; Caviness, 1973; Bayer and Altman, 1974; Hine and Das, 1974; Schlessinger et al., 1975; Stanfield and Cowan, 1979; Woodhams et al., 1981), and glial-guided neuronal migration (Nowakowski and Rakic, 1979; Eckenhoff and Rakic, 1984) are well-described, the molecular mechanisms of neuron-glia interactions in this region have not bcen analyzcd.

Here we have used a microculture system to analyze astroglial organization of hippocampal neuronal positioning, the mode of neuronal migration along hippocampal astroglial processes and neuronal regulation of hippocampal astroglial differentiation. The culture system and its analysis were adapted from previous studies by our laboratory on neuron-glia interactions of mouse cerebellar cells (Hatten and Liem, 1981; Hatten et al., 1984).

In this study, we have observed developmental stage-specific neuron-glia interactions in microcultures of hippocampal cells. The most striking neuron-glia relationship is the migration of young neurons along hippocampal glial processes in vitro. In addition, as seen for cerebellar glial cells (Hatten, 1985, 1987), 
and for astrocytoma cells derived from primary tumors which arose in different areas of human and rodent brain (Hatten and Shelanski, 1988), hippocampal neurons regulate the proliferation of hippocampal astroglial cells and induce their differentiation.

\section{Materials and Methods}

Cell culture. All studies were performed with hippocampal tissue harvested from Sprague-Dawley rats at embryonic (E) days 16-20 or on postnatal $(\mathrm{P})$ days $0-3$. A single-cell suspension was prepared as described for cerebellar cells (Hatten and Francois, 1981), after which the suspension was passed through a monofilament polyester screen $(33 \mu \mathrm{m}$ mesh size, Tetko Inc., Elmsford, NY) to remove cellular aggregates before rcsuspension in Eaglc's Basal Mcdium with Earle's salts (BME; Grand Island Biologicals, Grand Island, NY) supplemented with fetal bovine serum $(10 \%, \mathrm{GIBCO})$ or horse serum $(10 \%$, GIBCO), glutamine (4 mM, GIBCO), glucose $(8 \mathrm{~mm})$, and penicillin-streptomycin $(20$ units $/ \mathrm{ml}$, GIBCO). Cells were plated at a final cell density of $1 \times 10^{\circ}$ cells $/ \mathrm{ml}$ in a final volume of $50 \mu \mathrm{l}$ in glass coverslip microcultures (Hatten and Francois, 1981) or of $150 \mu \mathrm{l}$ in Labtek chamber slides (Miles Scientific, Division of Miles Laboratories, Naperville, IL). A second coverslip was placed over the culture well in the glass coverslip microcultures just after the cells were plated. Cultures were maintained at $35.5^{\circ} \mathrm{C}$ with $100 \%$ humidity and $5 \% \mathrm{CO}_{2}$.

Prior to the addition of the cells, the culture surface was pretreated overnight with polylysine (Sigma, St. Louis, MO, plys, 25-100 $\mu \mathrm{g} / \mathrm{ml}$ ), polyornithine (Sigma, porn $25-100 \mu \mathrm{g} / \mathrm{ml}$ ), or Matrigel (Collaborative Research, Inc., Lexington, MA; dilution 1:25-1:100, $45 \mathrm{~min}$ at $37^{\circ} \mathrm{C}$ ). Subsequently, the dishes were washed three times with $\mathrm{H}_{2} \mathrm{O}$ and airdried.

Video-enhanced differential interference microscopy. For video microscopy, hippocampal cells were harvested on E20 and plated in glass coverslip microcultures pretreated with Matrigel. After $24 \mathrm{hr}$ in vitro, the medium was changed to L15 medium supplemented with horse serum $(10 \%)$ and glucose $(8 \mathrm{~mm})$, and the chamber was sealed with a second coverslip as described (Edmondson and Hatten, 1987). The behavior of bipolar neurons which were closely apposed to glial fibers was observed with video-enhanced differential interference contrast microscopy (Edmondson and Hatten, 1987). The image was recorded on a Panasonic Memory Disk Recorder with a Hamamatsu Chalnicon video camera mounted on a Zeiss Axiovert microscope fitted for Nomarski optics. A Zeiss Plan-Neofluor $100 \times / 1.3$ oil-immersion objectivc was used. An Image-1 computer system was used to enhance and pair the images for still photography of selected frames, as well as to drive the memory disk recorder at a speed of 1 frame/sec. As described previously (Edmondson and Hatten, 1987), after imaging neuronal migration, we scribed the field and immunostained with antibodies against the glial filament protein (see below) to contirm that the process on which the cells migrated was glial in origin.

Immunostaining with cellular antigen markers. To identify astroglial cells in the cultures, the cells were immunostained with antibodies against the glial filament protein (AbGFP), generously provided by our colleague Dr. R. K. H. Liem. All immunostaining procedures were carried out $24 \mathrm{hr}$ after the cells were plated. Neurons were identified by light microscopy and by immunostaining with antibodies against the NILE glycoprotein (AbNILE; Salton et al., 1983), generously provided by our colleagues Drs. Lloyd Greene and M. L. Shelanski. Procedures were as previously described using the PAP method (Hatten and Liem, 1981; Hatten et al., 1984). After dehydration in ethanol, the coverslips were mounted on glass slides.

Purification of hippocampal astroglial cells. To purify astroglial cells, $50 \mu \mathrm{l}$ of the cell suspension dissociated from hippocampal tissue was diluted to a final cell concentration of $3 \times 10^{6} \mathrm{cells} / \mathrm{ml}$, added to a Labtek chamber slide well, and incubated for $30 \mathrm{~min}$ (on pLys) or for 45-60 min (on Matrigel). Subsequently the dish was gently rapped against the lab bench 3-5 times, until most of the neurons were suspended, after which the neurons were removed by gentle washing with culture medium. The purity of the glial cultures was assessed by phase-contrast microscopy and, later, by immunostaining the cells with AbGFP or AbNILE; Salton et al., 1983. In the experiments reported, the astroglial preparations we analyzed contained less than $2 \%$ neuronal cells.

Quantitation of glial morphology and neuron-glia interactions. After immunostaining with AbGFP to identify astroglial cells and their processes, the length of stained glial processes was measured using a Leitz
Table 1. Survival of hippocampal cells dissociated at different developmental stages

\begin{tabular}{llll} 
& E16-E18 & E19-E20 & P0-P3 \\
\hline 1. Plating efficiency & 90 & $90-95$ & 80 \\
2. AbGFP-positive cells & $2-5$ & 15 & 25
\end{tabular}

Hippocampal tissue was dissociated into a single cell suspension at E16-E18, E19E20, or PO-P3 and plated in microcultures. After $24 \mathrm{hr}$ in vitro, the number of viable cells, measured by their exclusion of the dye Trypan blue, or the number of astroglial cells, visualized by immunostaining with anti-GFP antibodies, was counted by microscopy. The plating efficiency, calculated by expressing the number of viable cells as a percentage of the cells plated, is higher for cells from embryonic ages than for cells from postnatal tissue. The number of AbGFP-positive astroglia cells in the culture increased for cells harvested at later developmental stages.

Dialux 20 EB microscope, a Hipad Digitizer, an IBM PC and the Bioquant System IV (R\&M Biometrics Inc., Nashville, TN). The distribution of glial cells with a bipolar shape, bearing processes $30-50 \mu \mathrm{m}$ in length, of elongated cells with processes longer than $50 \mu \mathrm{m}$ or stellate cells with 3 or more processes $30-50 \mu \mathrm{m}$ in length was then measured. Results are from duplicate samples of 400-650 stained cells each.

To quantitate neuron-glia interactions, we measured the distance between a given neuron and the nearest AbGFP-positive cell or process. The distribution of neurons at given distances from stained glial processes was then plotted as described by Hatten and Liem (1981). For all of these experiments, the cclls were plated at a final cell density of $1 \times 10^{6}$ cells $/ \mathrm{ml}$, a density where approximately $20 \%$ of the total surface area of the culture dish was occupied by cells and their processes. The results of these studies are a combination of 3 replicate experiments evaluating a total of $400-650$ astrocytes per sample.

\section{Results}

When single-cell suspensions of embryonic and early postnatal rat hippocampus were plated in microcultures, the number of astroglial cells, the extent of glial morphological differentiation and of cell-cell interactions with neurons were developmentalstage specific. Measurements of the plating efficiency of cells harvested at different ages showed that total cell survival was maximal when the cells were dissociated from E19-E20 hippocampal tissue (Table 1). The key features of the microcultures were plating the cells at high density $\left(1 \times 10^{6}\right.$ cells $\left./ \mathrm{ml}\right)$, in a small volume $(50 \mu 1)$, in a culture medium supplemented with relatively high glucose concentrations and either fetal calf or horse serum (Hatten and Francois, 1981).

\section{Developmental stage-specific changes in hippocampal astroglial morphology in vitro}

When cultures of E16 hippocampal cells were immunostained with antibodies against the glial filament protein, a cellular antigen marker for astroglial cells, $2-5 \%$ of the total cell population was stained (Table 1). The majority of cells in the cultures were stained with anti-NILE antibodies (Salton et al., 1983), an antigen marker for neurons. The intensity of staining with AbGFP was relatively weak compared with cells harvested from later ages and was confined to the perinuclear region, the pattern of staining often appearing as a nuclear cap. Some of the stained cells expressed a bipolar shape, bearing very short processes (Fig. 1A). Similar results were seen with cells harvested from hippocampal tissue at E18.

When the cells were harvested from hippocampal tissue at E19 or E20, a very different picture emerged. Approximately $15 \%$ of the cells were immunopositive for AbGFP (Table 1), and astroglial cells resembling those seen in hippocampal tissuc at this developmental stage were evident (Fig. $1 B$ ). To analyze 


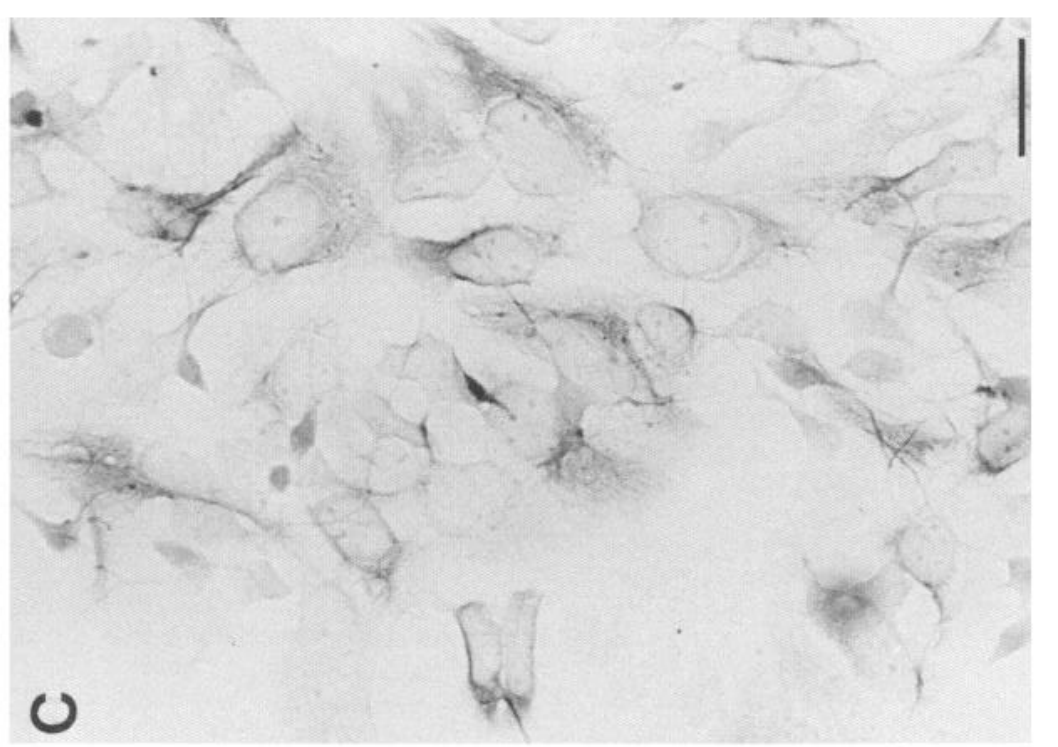

龸
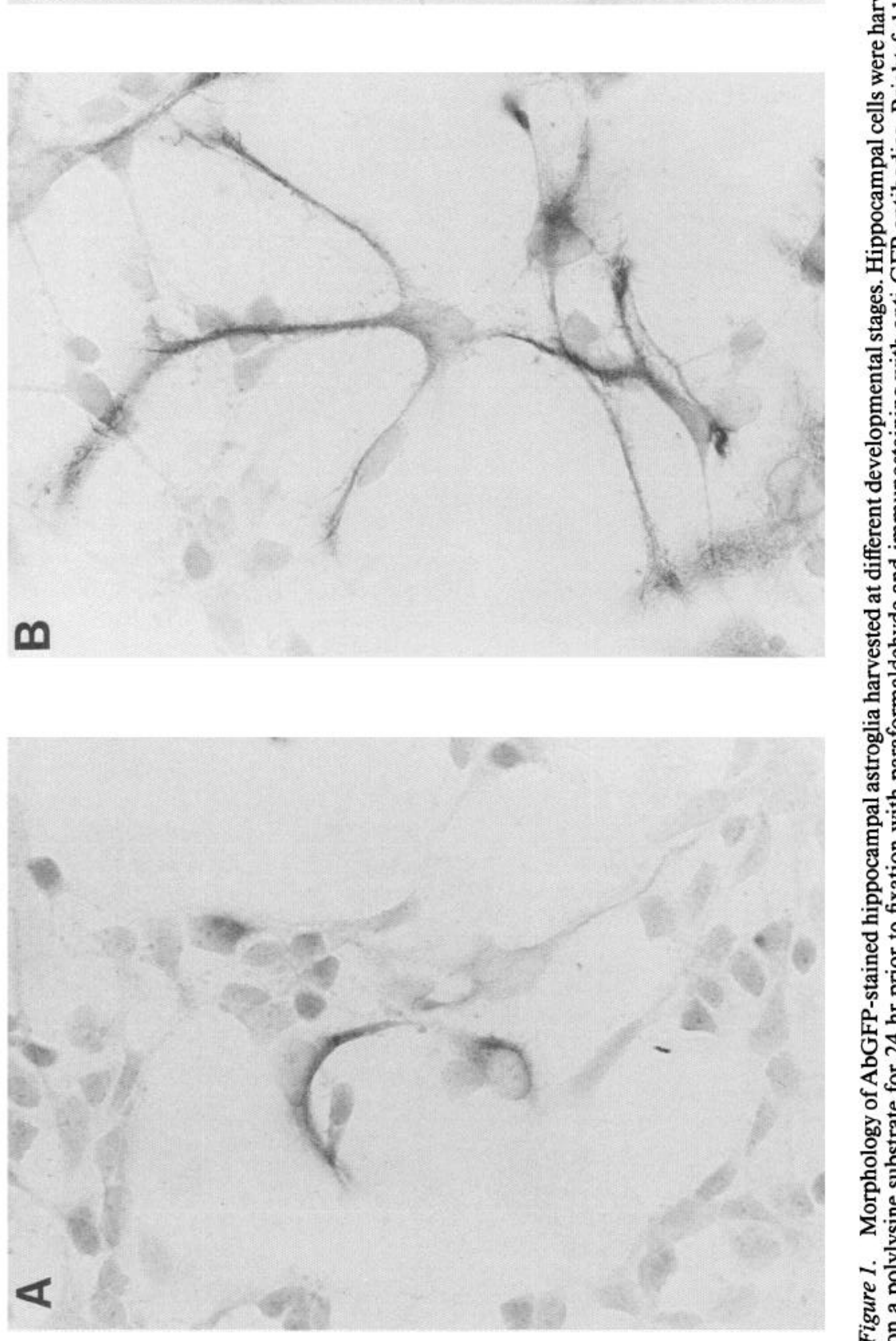

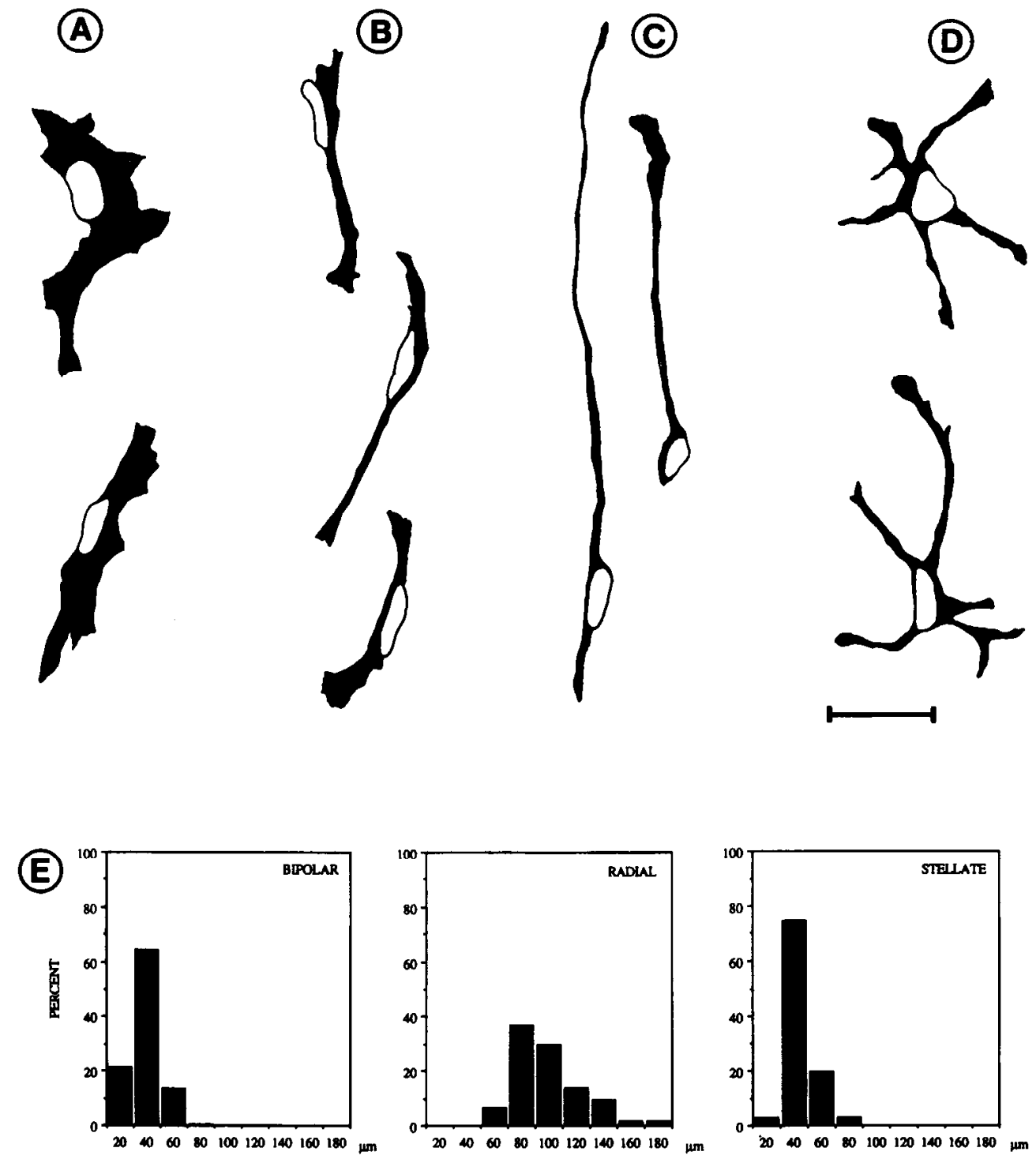

Figure 2. Camera lucida drawings of AbGFP stained cells in cultures of E20 hippocampal cells. Cells were dissociated from E20 hippocampus and plated in microcultures on a polylysine substrate for $24 \mathrm{hr}$ prior to immunostaining with AbGFP. $A$, Undifferentiated glial forms with a flat morphology. These cells constitute less than $5 \%$ of the total number of AbGFP-stained cells present. The predominant glial forms seen in the cultures include a bipolar form $(B)$, an elongated radial form $(C)$, and a stellate form $(D)$. In $E$, a Bioquant Image Analysis System was used to quantitate the process lengths of $B$ and $C$ in randomly sampled sets of $400-650$ stained astroglial cells (see text). the shape of glial forms present in cultures of E20 hippocampal cells and to determine whether these forms resembled forms seen in vivo, camera lucida drawings of AbGFP-immunostained glial cells were prepared. Although fine variations in glial form were common, drawings of randomly sampled sets of several hundred cells from a large series of cultures revealed that 3 basic forms predominated - a bipolar form, an elongated radial form, and a stellate form.

We defined the forms by the number and length of their processes as recorded in camera lucida drawings and used a Bioquant Image Analysis System to count the number of stained glial cells with those dimensions in samples of 400-650 stained glia (Fig. 2). These counts suggested that the majority of the intensely stained astroglia were bipolar with processes 30-50 $\mu \mathrm{m}$ in length. A second class of stained glia, highly elongated, radial cells, bearing processes as long as $120 \mu \mathrm{m}$, resembled radial glial cells seen in the hippocampal formation and the fimbria in vivo, forms proposed to support hippocampal neuronal migration during development (Woodhams et al., 1981; Eckenhoff and Rakic, 1984). A third class of stained cells ex- pressed a stellate morphology, bearing processes $30-50 \mu \mathrm{m}$ in length, and thereby resembled hippocampal astrocytes.

When hippocampal cells harvested from early embryonic tissue (E16-E18) were maintained in microcultures for 48-96 hr before immunostaining with AbGFP, the number of stained cells increased to the levels seen when the cells were harvested at E19-E20 and cultured for $24 \mathrm{hr}$, and the form of stained astroglial cells shifted from a lightly staincd, round or bipolar form to a mixture of intensely stained, differentiated cells having bipolar, radial, or stellate appearance (data not shown).

When cultures were prepared from hippocampal cells harvested from early postnatal animals (P0-P2), on a polylysinecoated surface, although the number of AbGFP-positive cells was high, approximately $25 \%$ of the total cell population (Table 1), stained cells expressed a flat, extended shape lacking distinct processes (Fig. $1 C$ ). The intensity of AbGFP staining of $\mathrm{P} 0$ glia was less than that seen for cells harvested at E19-E20.

For glial process extension to occur in cultures of P0-P3 cells, we had to treat the culture surface with Matrigel. On this culture surface, differentiated glial forms resembling those observed when 

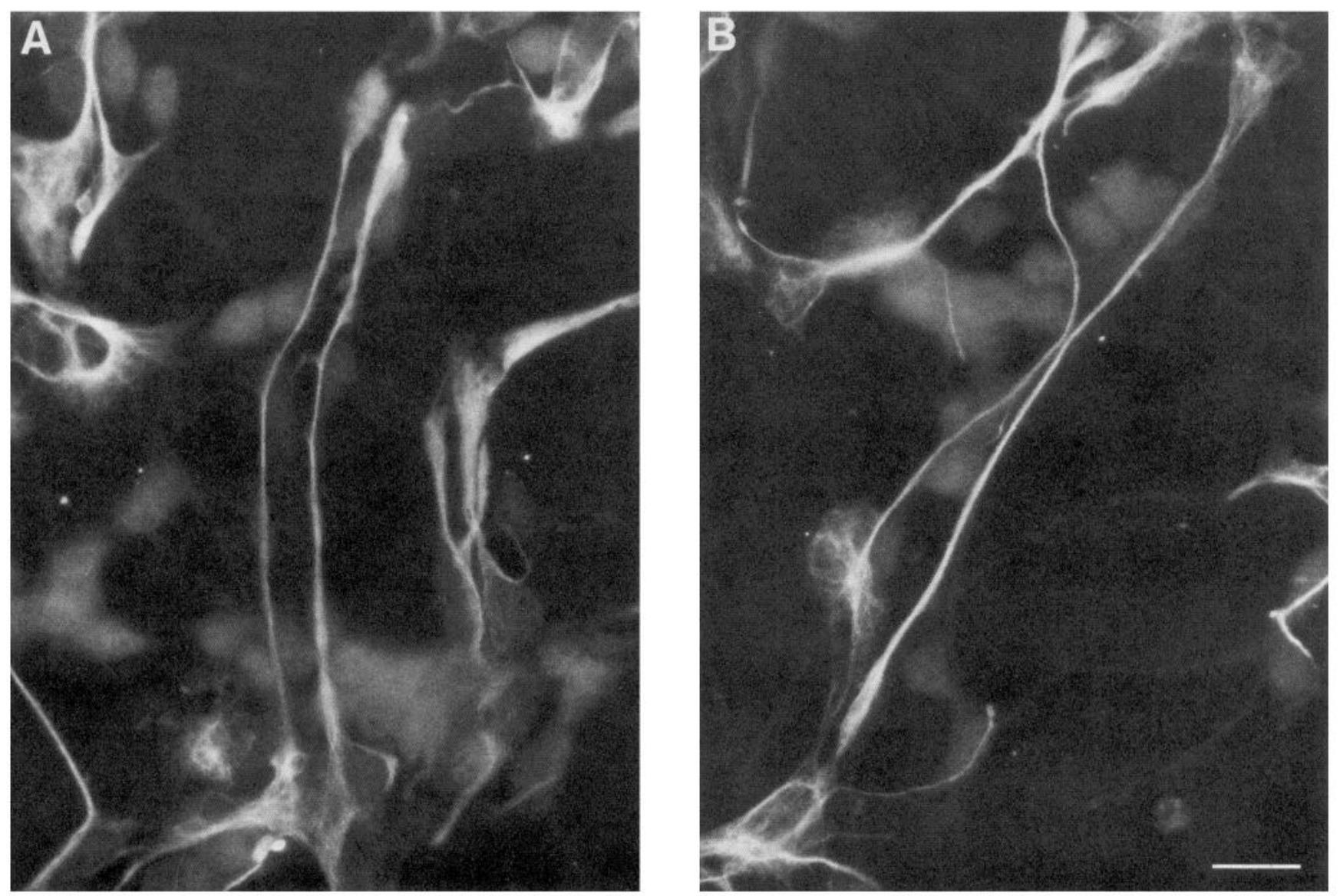

Figure 3. P0 astroglia differentiate on a culture surface treated with Matrigel. Hippocampal cells were harvested at P0 or E20, plated on Matrigel, maintained in microcultures for $24 \mathrm{hr}$, and immunostained with AbGFP. On Matrigel, AbGFP-positive cells from P0 $(A)$ resemble AbGFP-positive cells seen at E20 (B). Epifluorescent illumination. Scale bar, $10 \mu \mathrm{m}$.

the cells were harvested at E19-E20 were seen, and expression on GFP, as measured by the level of staining with AbGFP, increased dramatically. The predominant glial form seen when P0 cells were plated on Matrigel was an elongated, radial-like cell (Fig. 3).

\section{Astroglial organization of hippocampal neurons in microcultures}

To assess neuron-glia interactions, we measured the distribution of neurons relative to AbGFP-positive astroglial cells, or their processes, by the methods described for dissociated mouse cerebellar cells (Fig. 4). As seen for cerebellar cells, measurements of neuron-glia interactions had to be made at cell densities where the total area of the dish occupied by cells and their processes was less than $20 \%$. This occurred when the cells were plated at cell densities of $1 \times 10^{6} \mathrm{cells} / \mathrm{ml}$. Above that cell density, precise measurements could not be made.

In cultures of hippocampal cells harvested between E16 and E18 and plated on a culture surface treated with polylysine, the neurons were randomly distributed on the culture surface and did not preferentially associate with glial cells or their processes. At E20, the time when differentiated glial forms resembling those observed in vivo are present in the cultures, the vast majority of the neurons were located within $10 \mu \mathrm{m}$ of astroglial cells and their processes (Fig. 4). Many neurons (65\%) in the culture were directly apposed to glial arms.
On surfaces treated with polyamines (polylysine and polyornithine), the majority of P0 hippocampal neurons were randomly distributed on the culture surface and were not associated with glia. The affinity of P0 neurons for glial cells increased dramatically when the cells were cultured on Matrigel, where $90-95 \%$ of the total number of neurons present in the cultures clustered on glial structures.

Glial-guided neuronal migration of hippocampal cells in vitro Among the neurons which contacted AbGFP-positive glial cells in the cultures, a small number $(5-10 \%)$ had the elongated, bipolar shape characteristic of migrating neurons (Fig. 5). Migrating profiles were most common when the cells were harvested at E20 and cultured on coverslips coated with Matrigel (1:100). To study the behavior of hippocampal neurons along hippocampal glial processes, in particular to determine whether glial-guided neuronal migration occurred and to examine the mode of migration of hippocampal neurons on glial processes, we used video-enhanced, differential interference microscopy.

With video-enhanced differential interference microscopy, we observed glial-guided migration of both the more numerous small, presumptive granule neurons present in the cultures and of the larger neurons. The migration of a large neuron along an astroglial fiber is illustrated in Figure 6 . The cell body of the migrating neurons was highly extended on the glial arm. The neuron appeared to contact the glial fiber along the length of 


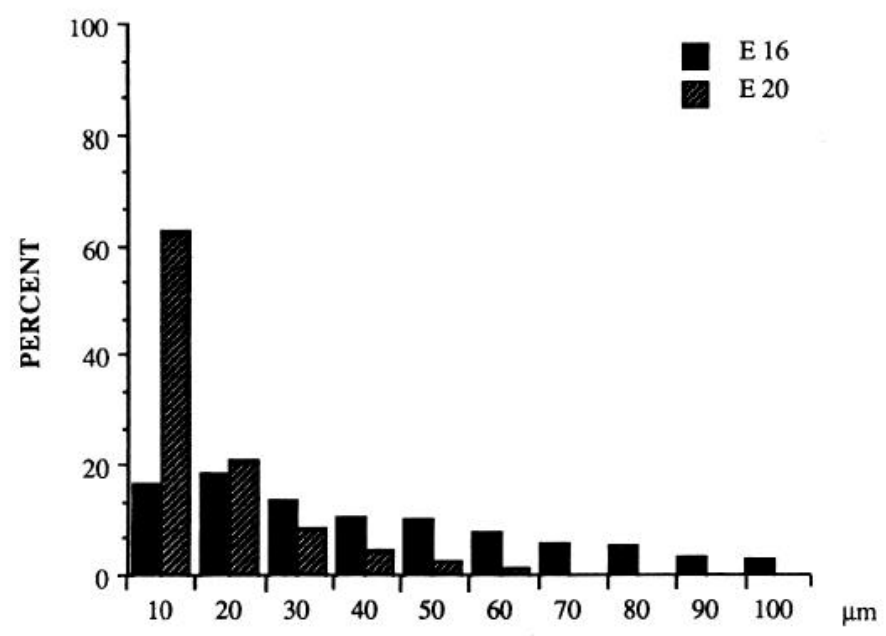

Figure 4. Neuron-glia interactions of hippocampal astroglial in vitro. Cells were harvested at E16 or E20 and plated in microcultures on a surface treated with polylysine at a density of $1 \times 10^{6} \mathrm{cells} / \mathrm{ml}$. After $24 \mathrm{hr}$ in vitro, the cultures were immunostained with AbGFP and a Bioquant Image Analysis system was used to measure the distance between neurons and stained glial processes (Hatten and Liem, 1981). The distribution of distances of E16 (solid bars) and E20 (striped bars) hippocampal neurons from stained glial processes reveals a close association of E20, but not of E16 cells, with astroglia.

the cell soma and extended a leading process in the direction of migration. As the neuron moved along the glial fiber, it maintained contact with the glial process along the length of its ell soma. The leading process was thin and tapered along its length, with numerous short filopodia $1-5 \mu \mathrm{m}$ in length.

Frame-by-frame analysis of the video recordings showed that the forward movement of the migrating neuron was in synchrony with extensions and contractions of the neuronal soma along the neuron-glia apposition. The frequent extensions and retractions of the tip of the leading process were random relative to the forward movement of the neuron along the glial fiber. Thus the leading process did not appear to "push" or "pull" the cell along the glial fiber.

By light microscopy, there were no major differences in the cytology or mode of movement of large neurons along glial fibers as compared with that of small, hippocampal granule neurons. The average speed of hippocampal neuronal migration along astroglial fibers varied between 20 and $60 \mu \mathrm{m} / \mathrm{hr}$. As seen for cerebellar cells, although many cells in the culture appeared to be migrating, only $5-10 \%$ of the neurons were actually in motion at any given moment. Migrating cells accelerated rapidly from a full stop to reach speeds of $50-60 \mu \mathrm{m} / \mathrm{hr}$ and then would often stop suddenly, pausing for periods as long as an hour before beginning to move again. The signals which initiated and terminated migration were not apparent by microscopy. Overall, the posture of the migrating hippocampal neuron, its relationship with the glial fiber, its mode of movement, and speed of migration closely resembled that of cerebellar granule cells migrating along cerebellar glial fibers in vitro (Edmondson and Hatten, 1987; Gregory et al., 1988).

\section{Influence of neurons on hippocampal astroglial cell differentiation}

Since previous studies with cerebellar cells had shown that astroglial differentiation is induced by cell-cell contact with neu-

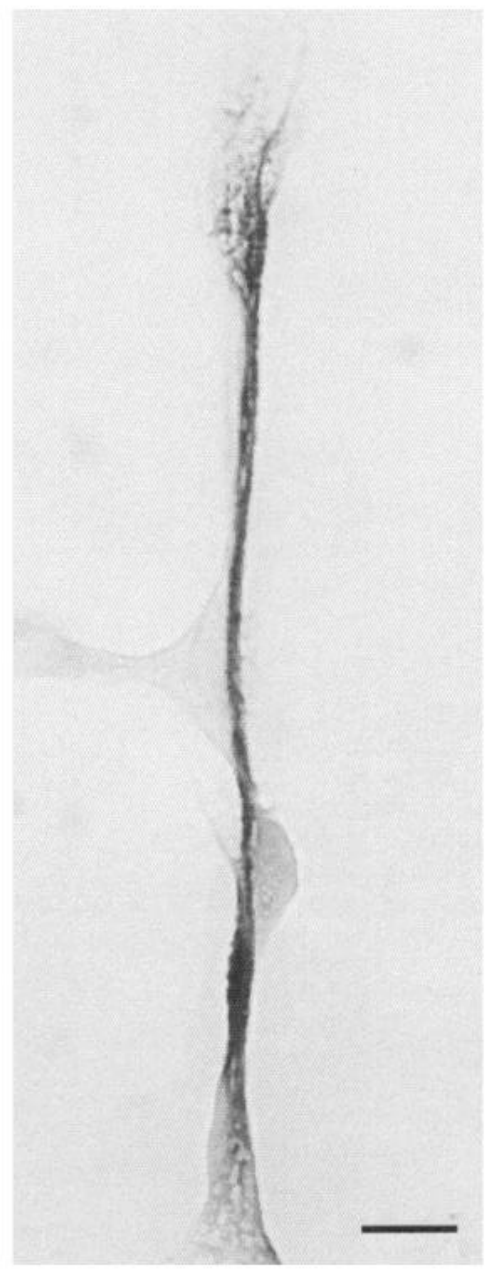

Figure 5. Hippocampal neurons with the neuron-glia relationship of migrating cells. E20 cells were plated in microcultures on a Matrigel substrate for $24 \mathrm{hr}$ and stained with AbGFP. An unstained cell with the cytology characteristic of a migrating neuron is seen apposed to a stained glial fiber. Nomarski optics enhanced with a Hamamatsu Chalnicon camera, Scale bar, $10 \mu \mathrm{m}$.

rons (Hatten, 1985, 1987; Hatten and Shelanski, 1988), we examined the influence of hippocampal neurons on hippocampal astroglial cell morphological differentiation. To do this, we purified hippocampal glia from E20 rats by preplating in LabTek chamber slide wells coated with polylysine or Matrigel. On either of these substrates, AbGFP-positive cells expressed a flat shape and did not extend processes.

Immunostaining of purified E20-P3 glia with AbGFP was weaker and more diffuse than that seen in age-matched cocultures of hippocampal neurons and glia (Fig. 7, $A, B$ ). As observed for cerebellar glia cultured in the absence of neurons, hippocampal astroglial cells proliferated rapidly (Fig. 7C). Growth was arrested when the glia were cocultured with neurons. The effect of neurons on glial cell differentiation was apparently reversible, since flat glial forms recurred when we either removed the neurons by washing or allowed the neurons to die by maintaining the cultures for periods longer than several days in vitro without refeeding (not shown). 
Figure 6. Video-enhanced differential interference microscopy of the migration of a large hippocampal neuron along an astroglial fiber. The neuron $(n)$ contacts the glial fiber $(g)$ along the interface with the neuronal cell soma and extends a leading process $(l p)$ in the direction of migration. Filopodia are commonly seen in the leading process and organelles move from the prenuclear region down into the leading process. Nomarski image recorded on a Panasonic Optical Memory Disk Recorder with a Hamamatsu Chalnicon camera mounted on a Zeiss Axiovert microscope equipped with Nomarski optics, a Zeiss Plan-Neofluor $100 \times / 1.3$ oil-immersion objective. Real time elapsed $(\mathrm{min})$ is indicated on each frame. Scale bar, $10 \mu \mathrm{m}$.

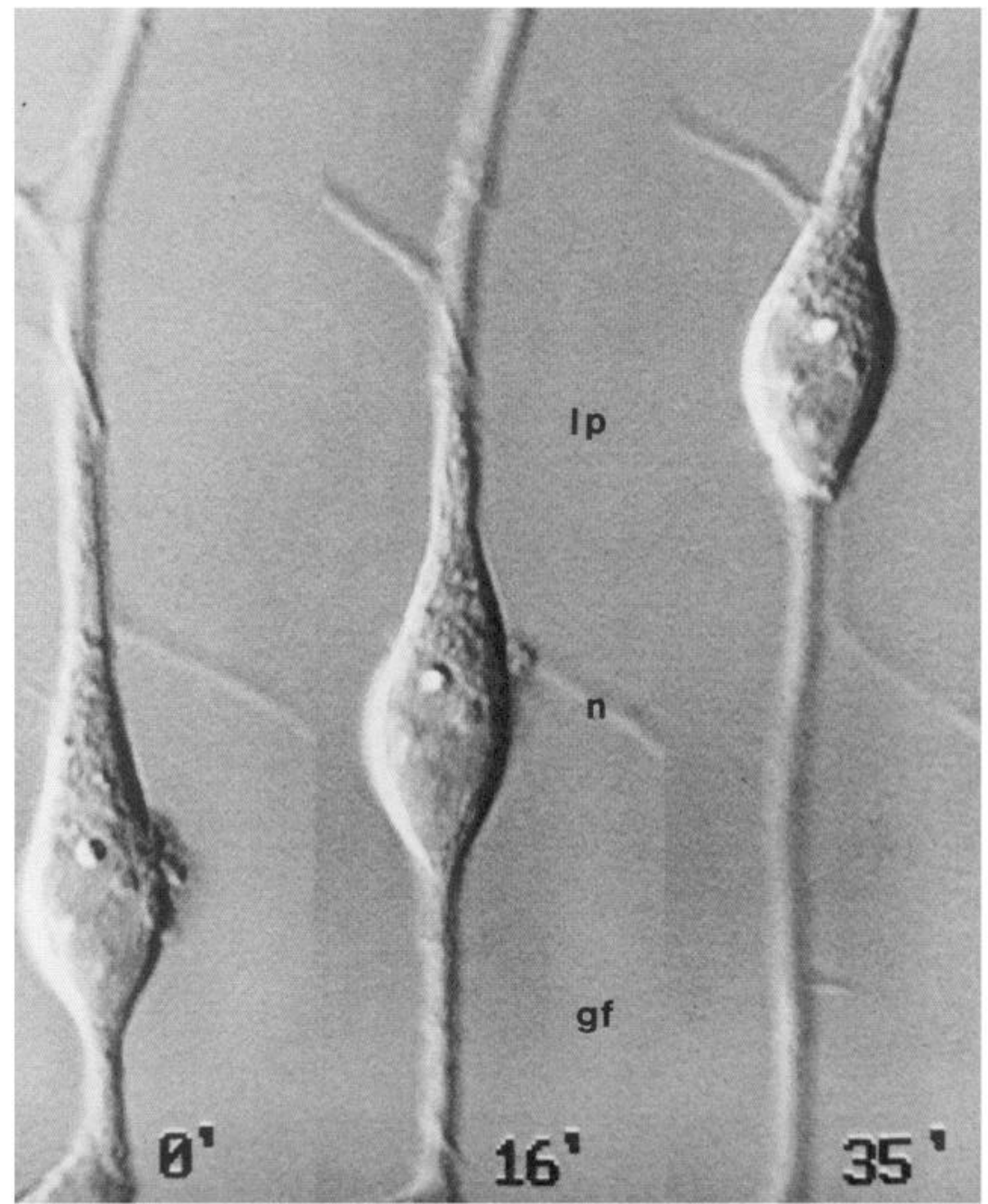

\section{Discussion}

Hippocampal neuron-glia interactions in vitro

These studies suggest that hippocampal neuron-glia relationships are stage-specific and are accompanied by astroglial morphological differentiation. As seen for cerebellar cells (Mason et al., 1988), rat hippocampal astroglial cells attain complex shapes by the outgrowth of processes, induced by cell-cell contact with neurons.

An important finding in this study was that glial-guided migration occurs in microcultures of E19-E20 hippocampal cells, particularly when the cells are plated on Matrigel. The cytology and mode of migration of both small and large hippocampal neurons along astroglial processes in vitro very closely resembled that described for cerebellar granule neurons. In addition, the cytological features of migrating cells resembled those described by Nowakowski and Rakic (1979) for hippocampal neuronal migration in vivo. A key feature of the migrating neuron appeared to be the formation of a site of cell-cell contact underneath the neuronal cell soma and the extension of a leading process in the direction of migration. The finding that the motions of the leading process were not synchronized with the forward movement of the neuron along the glial guide is consistent with studies on cerebellar cells (Edmondson and Hatten, 1987; Hatten, 1990) and suggests that the leading process does not "push" or "pull" the neuron along the glial fiber. Instead movement appears to be generated along the neuron-glia apposition at the cell soma.

Another important feature of hippocampal neuronal migration in vitro was the finding that migration occurred only on bipolar, elongated glial profiles. This finding is consistent with our previous results with cerebellar cells (Hatten et al., 1984) and suggests that the geometry of the glial fiber is an important aspect of glial-guided neuronal migration.

Figure 7. Influence of neurons on hippocampal astroglial cell growth and differentiation. Astroglia purified from E20 rat hippocampus $(A)$ express a flat morphology when cultured in the absence of neurons but differentiate into forms resembling those seen in vivo when cocultured with hippocampal neurons. In $c$, the growth rate of glial cells cultured in the absence of neurons $(\square)$ is rapid. In coculture with neurons ( $)$ ), glial growth is arrested. Cells were plated in microcultures on a polylysine substrate and immunostained with AbGFP after 1-3 d in vitro, after which immunostained cells were either photographed (shown here after $24 \mathrm{hr}$ in vitro) or counted by light microscopy. Scale bar, $10 \mu \mathrm{m}$. 

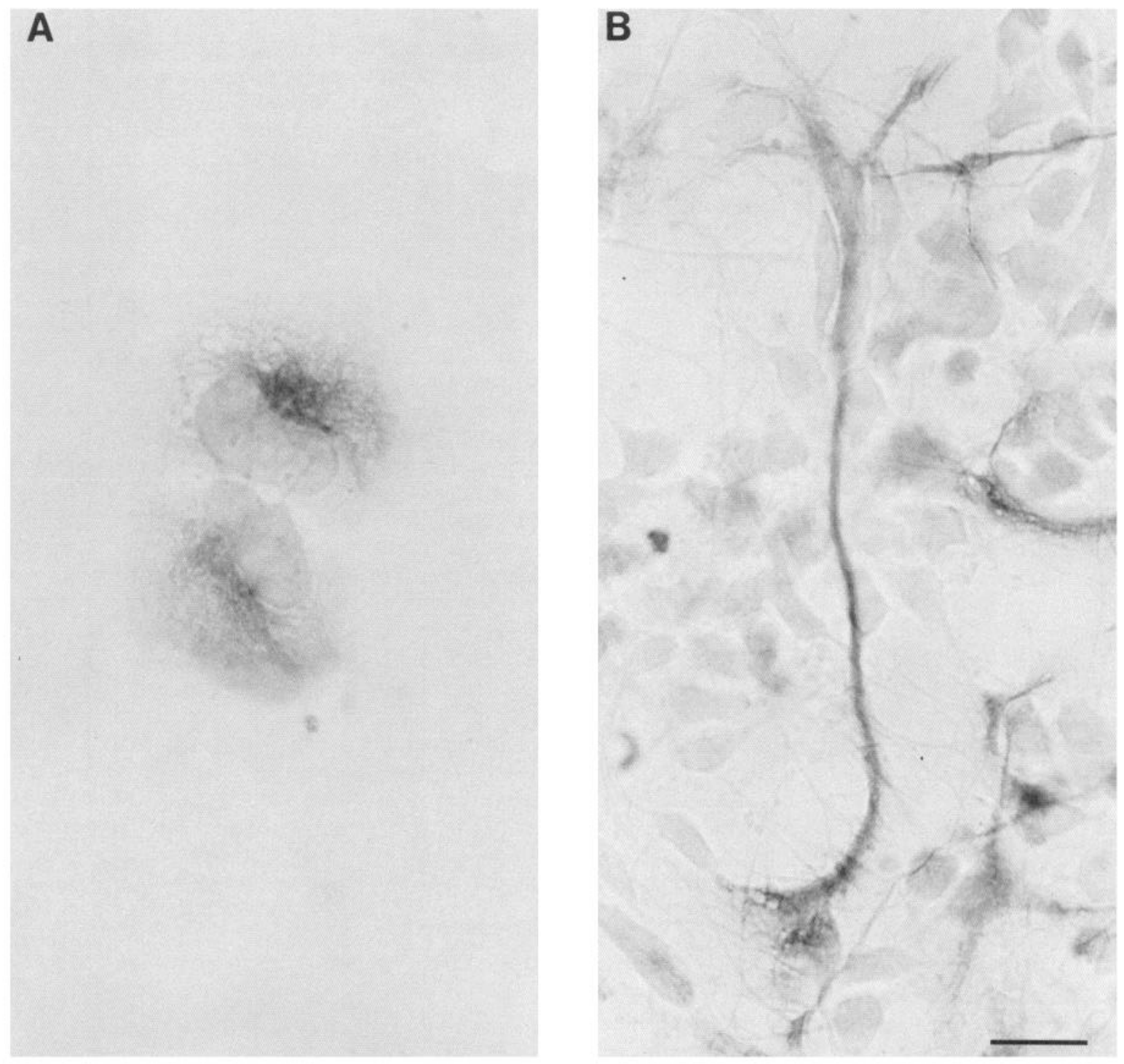

(c)
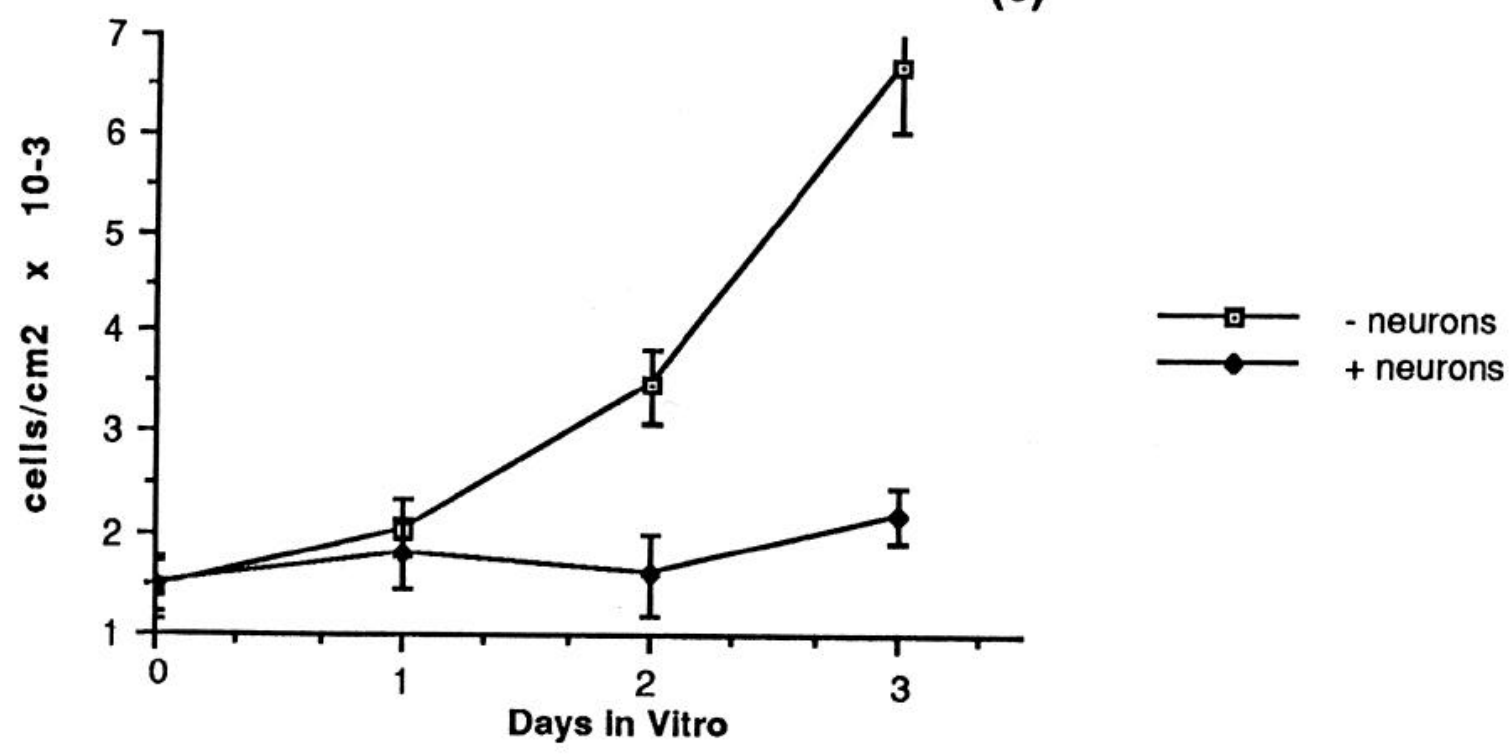
The present studies suggest that the cytology and mode of neuronal migration along glial processes are stereotyped in these 2 brain regions. To test the regional specificity of glial-guided neuronal migration, we have recently "mixed and matched" granule neurons purified from cerebellum with glial cells purified from hippocampus and analyzed glial-guided migration in heterotypic cocultures (U. E. Gasser and M. E. Hatten, unpublished observations). These studies show that granule cells migrate on hippocampal glia and vice versa and that the mode of neuronal migration along glia from heterotypic brain regions closely parallels that observed here for hippocampal neurons and that reported previously for cerebellar cells (Hatten, 1989).

\section{Hippocampal astroglial morphological differentiation in vitro}

The influence of the culture substrate on the length of glial processes suggests that glial process extension, like neurite extension (Rogers et al., 1983), depends on the availability of an adhesive surface, and varies when the cells are plated on polylysine or Matrigel. The finding that different glial forms are seen when cells are harvested from early embryonic as compared with late embryonic hippocampus, and that over time in culture these forms differentiate into forms seen when the cells are harvested at E19-E20, is similar to our results with cerebellar cells (Hatten, 1983) and to those of Abney et al. (1981) with glia from the optic nerve. In both of those studies, glial cells resembling those seen in vivo could be visualized when the cells were kept in culture for 3-5 d prior to immunostaining with AbGFP.

The finding that immunostaining of astroglial cells with AbGFP is somewhat delayed relative to the time at which radial cells can be visualized with Golgi methods is consistent with other studies showing that glial filament expression is a rather late marker for astroglial cells (Bovolenta et al., 1984). Indeed, in most regions of the developing rodent brain, AbGFP-positive cells are not seen until after glial-guided migration begins (Schnitzer et al., 1981). In both hippocampus and cerebellum, the late glial-guided migration of the granule neurons is guided by AbGFP-positive glia, and these glial cells can be identified in microcultures with AbGFP staining (Bovolenta et al., 1984; Eckenhoff and Rakic, 1984; Hatten et al., 1984).

In the present study, owing to the absence of specific cellular antigen markers for the hippocampal neurons in the cultures, precise classification and identification of the neurons was not possible. By light microscopy, both small neurons, which were likely to represent hippocampal granule cells, and large neurons, which probably included pyramidal and other hippocampal neurons, were present when the cells were dissociated at E19E20 (Banker and Cowan, 1977; Banker and Cowan, 1979), and both formed contact relationships with astroglial cells.

As seen for cerebellar cells (Hatten, 1985, 1987), hippocampal astroglia expressed undifferentiated forms in the absence of neurons, collapsing into flat, proliferating cells but differentiating into forms resembling those seen in vivo when hippocampal neurons were cocultured with purified glia. This result suggests that neuronal induction of astroglial differentiation occurs in a variety of brain regions. This interpretation is consistent with our recent studies with astrocytoma cells, which showed that cerebellar granule cells arrest the growth of glioma cells derived originally from a variety of brain regions and from both rodent and human brain (Hatten and Shelanski, 1988).

\section{Regional specificity of neuron-glia interactions}

The model that emerges from these studies is that astroglial cells of different forms occur in different brain regions, that the timetable of glial morphological differentiation parallels their role in supporting neuronal migration and positioning. Thus for hippocampal cells in vitro, elongated glial profiles predominate in the late embryonic period. By the later embryonic period, a period of intense neuronal migration in vivo, astroglial forms are common in the cultures and neurons preferentially associate with the glia compared with the culture surface. The extent of neuron-glia interaction varies with the substrates on which the cells are cultured, but in general, neuron-glia association is highest in cultures from this developmental stage as compared with earlier or later periods.

A key issue is whether therc is a large number of families of glia in different brain regions or whether there is a small set of glial cells, with different timetables of differentiation in different brain regions. The present experiments suggest that there are differences in the morphology of glia from hippocampus and cerebellum, differences that are expressed when the cells are placed into culture. It remains to be shown whether these forms represent distinct "lypes," i.e., lineages of glia in hippocampus.

These studies suggest that neuron-glia interactions, including the coordination of astroglial morphological differentiation with glial support of neuronal positioning, neuronal induction of glial differentiation, and the model of glial-guided neuronal migration are common among brain regions. This in vitro model system for hippocampal cells, together with culture systems developed to study cerebellar cells, and with recent experiments on cocultures of neurons and glia from different brain regions, should facilitate the identification of receptor systems involved in neuron-glia interactions among brain regions.

\section{References}

Abney, E. R., P. B. Bartlett, and M. C. Raff (1981) Astrocytes, ependymal cells and oligodendrocytes develop on schedule in dissociated cell cultures of embryonic rat brain. Dev. Biol. 83: 301-310.

Altman, J., and G. D. Das (1965) Autoradiographic and histological evidence of postnatal hippocampal neurogenesis in rats. J. Comp. Neurol. 124: 319-336.

Angevine, J. B., Jr. (1965) Time of neuron origin in the hippocampal region. An autoradiographic study in the mouse. Exp. Neurol. 2: 117.

Banker, G. A., and W. M. Cowan (1977) Rat hippocampal neurons in dispersed cell culture. Brain Res. 126: 397-425.

Banker, G. A., and W. M. Cowan (1979) Further observations on hippocampal neurons in dispersed cell culture. J. Comp. Neurol. 187 . 469-494.

Bayer, S. A., and J. Altman (1974) Hippocampal development in the rat: Cytogenesis and morphogenesis examined with autoradiography and low-level X-irradiation. J. Comp. Neurol. 158: 55-80.

Barbin, G., D. M. Katz, B. Chamak, J. Glowinski, and A. Prochiantz (1988) Brain astrocytes express region-specific surface glycoproteins in culture. Glia $1: 96-103$.

Bovolenta, P., R. K. H. Liem, and C. A. Mason (1984) Development of cerebellar astroglia: Transitions in form and cytoskeletal content. Dev. Biol. 102: 248-259.

Caviness, V. S., Jr. (1973) Time of neuron origin in the hippocampus and dentate gyrus of normal and reeler mutant mice: An autoradiographic analysis. J. Comp. Neurol. 151: 113-120.

Eckenhoff, M. F., and P. Rakic (1984) Radial organization of the hippocampal dentate gyrus: A golgi, ultrastructural, and immunocytochemical analysis in the developing rhesus monkey. J. Comp. Neurol. 223: 11.

Edmondson, J. C., and M. E. Hatten (1987) Glial-guided granule neuron migration in vitro: A high-resolution time-lapse video microscopic study. J. Neurosci. 7: 1928-1934. 
Gregory, W. A., J. C. Edmondson, M. E. Hatten, and C. A. Mason (1988) Cytology and neuron-glia apposition of migrating cerebellar granule cells in vitro. J. Neurosci. 8: 1728-1738.

Hatten, M. E. (1983) Embryonic cerebellar astroglia in vitro. Dev. Brain Res. 13: 309-313.

Hatten, M. E. (1985) Neuronal regulation of astroglial morphology and proliferation in vitro. J. Cell Biol. 100: 384-396.

Hatten, M. E. (1987) Neuronal inhibition of astroglial cell proliferation is membrane mediated. J. Cell Biol. 104: 1353-1360.

Hatten, M. E. (1990) A common mechanism for glial-guided migration in different regions of the developing brain. Trends Neurosci., (in press).

Hatten, M. E., and A. M. Francois (1981) Cell assembly patterns of embryonic and early postnatal mouse cerebellar cells on lectin-derivatized culture substrata. Dev. Biol. 87: 102-113.

Hatten, M. E., and R. K. H. Liem (1981) Astroglia provide a template for the positioning of developing cerebellar neurons in vitro. J. Cell Biol. 90: 622-630.

Hatten, M. E., and M. L. Shelanski (1988) Mouse cerebellar granule neurons arrest the proliferation of human and rodent astrocytoma cells in vitro. J. Neurosci. 8: 1447-1453.

Hatten, M. E., R. K. H. Liem, and C. A. Mason (1984) Two forms of cerebellar glial cells interact differently with neurons in vitro. J. Cell Biol. 98: 193-204.

Hine, R. J., and G. D. Das (1974) Neuroembryogenesis in the hippocampal formation of the rat. Z. Anat. Entwickl.-Gesch. 144: 173186.

Issacson, R. L., and K. H. Pribram, eds. (1975) The Hippocampus, Vol. 1, Structure and Development, Plenum, New York.

Mason, C. A., J. C. Edmondson, and M. E. Hatten (1988) The extending astroglial process: Development of glial shape, the growing tip and interactions with neurons. J. Neursoci. 8: 3124-3134.

Nowakowski, R., and P. Rakic (1979) The mode of migration of neurons to the hippocampus: A Golgi and electron microscopic analysis in fetal rhesus monkeys. J. Neurocytol. 8: 697-718.

Rakic, P. (1971) Neuron-glia relationship during granule cell migration in developing cerebellar cortex. A Golgi and electron microscopic study in Macacus rhesus. J. Comp. Neurol. 141: 283-312.
Rakic, P. (1972) Mode of cell migration to the superficial layers of foetal monkey neocortex. J. Comp. Neurol. 145: 61-83.

Rakic, P. (1978) Neuronal migration and contact guidance in primate telencephalon. Postgrad. Med. J. 54: 25-40.

Ramón y Cajal, S. (1893) Estructura del Asta de Ammon y fascia dentata. An. Soc. Esp. Hist. Nat. 22: 53-114.

Rogers, S. L., P. Letourneau, C. Palm, S. L. McCarthy, and L. Furcht (1983) Neurite extension by peripheral and central nervous system neurons in response to substratum-bound fibronectin and laminin. Dev. Biol. 98: 212-220.

Salton, S. R. J., C. Richter-Landsberger, L. A. Greene, and M. L. Shelanski (1983) Nerve growth factor inducible large external glycoprotein (NILE), studies of a central and peripheral neuronal marker. J. Neurosci. 3: 441-454.

Schlessinger, A. R., W. M. Cowan, and D. I. Gottlieb (1975) An autoradiographic study of the time of origin and the pattern of granule cell migration in the dentate gyrus of the rat. J. Comp. Neurol. 159: 149-176.

Schnitzer, J., W. W. Franke, and M. Schachner (1981) Immunocytochemical demonstration of vimentin in astrocytes and ependymal cells of developing and adult nervous system. J. Cell Biol. 90:435447.

Silver, J., S. E. Lorenz, D. Wahlsten, and J. Coughlin (1982) Axon guidance during development of the great cerebral commissures: Descriptive and experimental studies, in vivo, on the role of preformed glial pathways. J. Comp. Neurol. 210: 10-29.

Stanfield, B. B., and W. M. Cowan (1979) The development of the hippocampus and dentate gyrus in normal and reeler mice. J. Comp. Neurol. 185: 423-460.

Tomaselli, K. J., K. M. Neugebauer, J. L. Bixby, J. Lilien, and L. F. Reichardt (1988) N-Cadherin and integrins: Two receptor systems that mediate neuronal process outgrowth on astrocyte surfaces. Neuron 1: 33-43.

Woodhams, P. L., E. Bascó E., F. Hajós, A. Csillág, and R. Balázs (1981) Radial glia in the developing mouse cerebral cortex and hippocampus. Anat. Embryol. 163: 331-343. 